\title{
Emprego da cerclagem com parafusos corticais na osteossíntese de mandíbula em equino - relato de caso
}

[a] Universidade Estadual de Maringá (UEM), Umuarama, PR, Brasil

[b] Centro Universitário de Maringá (UniCesumar), maringá, PR, Brasil

*Autor correspondente

e-mail: thais.ask@hotmail.com

\section{Resumo}

A laminite equina é ocasionada por inúmeros fatores, destacando-se os distúrbios gastroentéricos, envolvendo tanto processos inflamatórios e funcionais quanto a ingestão excessiva de grãos. Independente da etiologia, as manifestações clínicas incluem alteração cardiorrespiratória, pulso digital positivo, claudicação, alternância de apoio entre os membros e/ou decúbito, bem como, em casos severos, rotação e deslocamento ventral da falange distal. A terapêutica envolve administração de antiinflamatórios não esteroidais, anticoagulantes, antiendotóxicos, analgésicos e alterações alimentares. Todavia, vale ressaltar que a associação de técnicas alternativas para o controle da dor se faz necessária em casos mais severos, entre elas o emprego da farmacopuntura, a qual consiste na administração de subdoses de fármacos em pontos de acupuntura, proporcionando analgesia e potencializando os efeitos do fármaco utilizado. Foi atendido no Hospital Veterinário da Universidade Estadual de Maringá (UEM) , no campus Umuarama, um equino da raça Quarto de Milha, macho, 9 anos de idade, $450 \mathrm{~kg}$, atleta da modalidade "três tambores", com histórico de ingestão excessiva de aveia seguida de claudicação. Durante o exame físico, foi observado claudicação em grau 4 (0-5), pulso positivo das artérias digitais e aumento da temperatura da porção distal dos membros torácicos, bem como relutância em movimentar-se. Ao exame clínico, foi observada alteração da frequência cardiorrespiratória, sendo $40 \mathrm{bpm}$ e $24 \mathrm{mpm}$, respectivamente, indicando presença de dor. No exame radiográfico, foi identificada rotação de terceira falange, sendo 4.4 graus de rotação no membro torácico direito e 4.3 graus no membro torácico esquerdo. Como protocolo inicial de tratamento foi prescrito fenilbutazona (4.4mg/kg, IV, SID, durante sete dias), omeprazol ( $2 \mathrm{mg} / \mathrm{kg}$, VO, SID, durante 10 dias), ácido acetilsalicílico (10 mg/kg, VO, SID, durante 10 dias) e cetamina $(0,2 \mathrm{mg} / \mathrm{kg}, \mathrm{VO}, \mathrm{BID}$, durante sete dias). Entretanto, ao terceiro dia de tratamento, foi empregada a farmacopuntura, sendo administrado flunixin 
meglumine (0,27 mg/kg, SID) no acuponto Vaso Governador -1 (VG-1), pois o paciente estava arresponsivo aos analgésicos, permanecendo em decúbito por períodos prolongados. A escolha da farmacopuntura devese ao seu efeito antiálgico prolongado pela administração de fármacos nos acupontos, reduzindo a dose e potencializando os efeitos analgésicos e anti-inflamatórios do flunixin meglumine, logo reduzindo os efeitos colaterais ocasionados por doses convencionais, bem como os custos do tratamento e tempo de contenção do paciente. 0 paciente recebeu alta médica alguns dias depois, após o desmame dos fármacos. Podemos concluir que, neste caso, a farmacopuntura apresentou resultado satisfatório no controle da dor na laminite.

Palavras-chave: Acuponto. Analgesia. Dor. 